\title{
LINEAR AND ANGLE DISPLACEMENT MEASUREMENT OF VERTICAL MILLING CENTER USING A MULTI-AXIS CALIBRATOR
}

\author{
P. Maj ${ }^{*}$, E. Miko ***
}

\begin{abstract}
The paper presents the methodology results of measurements of the accuracy of movements of the linear axis of a CNC machine. The XM-60 multi-axis calibrator by RENISHAW was used as a research apparatus. It allows measurement in six degrees of freedom in any spatial orientation with one mounting. This translates into an increase in the accuracy of measurements performed due to the elimination of the need to adapt the test bench depending on the measurements performed. This made it possible to measure linear and angular displacements from one mounting of the test apparatus. Due to the repeatability of the measurement method for each of the CNC machine axes, the article presents the measurement and results of the $Y$ axis of the DMU50 vertical milling center.
\end{abstract}

Keywords: interferometer, multi-axis calibrator, CNC machine, milling machine, accuracy.

\section{Introduction}

Waste processing is one of the basic technological processes. It allows to perform basic machine elements. The pursuit of more and more accurate objects meant that the machines were to maintain the pre-given dimensional and shape accuracy of the produced objects. Regarding newly manufactured machines, these were the criteria that can be achieved. The industry currently has a large number of machines that do not maintain the declared machining parameters. To increase their usefulness, systems were created to enable the measurement of the diagnostic status of machines tools (Honczerenko, 2009 and Szafarczyk, 2005). It allowed to determine whether the machine performs its functions correctly. Also, an appropriate interpretation of the results would allow to determine which of the machine tool components negatively affect to the machining process. With the data it will be possible to repair or modernize the machine and give the option of adding an appropriate error compensation system. This will translate into increased accuracy of the machine tool. This type of system can also be used in new machine tools for periodic measurements of the machine's diagnostic status (Maj, 2014 and Miko, 2012).

The article aims to present the possibility of a diagnostic measurement of the displacements of the linear axis Y of a CNC machine. The Renishaw MX-60 multi-axis calibrator was used for these purposes. Due to its simplified construction, it is possible to carry out various types of measurements from a single clamping which shortened the time of testing and increased their accuracy. The test stand made possible to measure linear and angular displacements of the tested axis of the DMU50 machine tool.

\section{Measuring stand}

The machine tool under test was the vertical milling center DMU50 MonoBlock, equipped with the HEIDENHEIN iTNC530 control. It was a 5-axis CNC machine. The tests were carried out using Renishaw XM-60 research equipment. It is a device that allows measurement in six degrees of freedom in any spatial orientation with one mounting. This translates into an increase in the accuracy of

Piotr Maj, M.Sc.: Chair of Mechanical Enginnering and Metrology, Kielce University of Technology; Aleja Tysiąclecia Państwa Polskiego 7; 25-314 Kielce; PL, pmaj@tu.kielce.pl

** Edward Miko, Prof PŚk, dr hab.: Chair of Mechanical Enginnering and Metrology, Kielce University of Technology; Aleja Tysiąclecia Państwa Polskiego 7; 25-314 Kielce; PL, emiko@tu.kielce.pl 
measurements performed due to the elimination of the need to adapt the test bench depending on the measurements performed. The measurements were made by analyzing the interference of the laser beam.

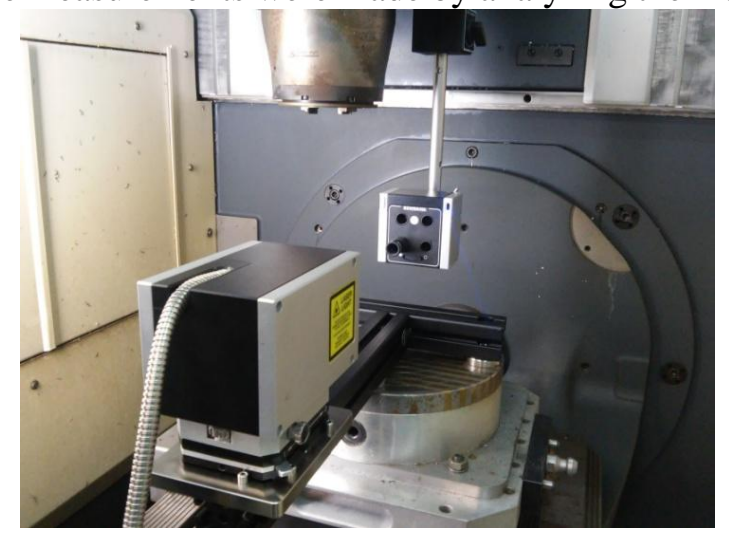

Fig. 1: Test stand for measurement of $Y$ axis displacements.

Using the mounting bracket, the laser beam emitting head was mounted on the machine table (Figure 1). A laser beam receiver was attached to the machine spindle with a magnetic holder. The machine has been programmed to make the spindle move along the $\mathrm{Y}$ axis. The movement was performed over a distance of $440 \mathrm{~mm}$. During the movement, every $22 \mathrm{~mm}$ there was a temporary stop, where the apparatus measured. The displacement was carried out in two directions. The trip has been repeated 7 times. The test stand allowed to measure linear and angular displacement of the $\mathrm{Y}$ axis in one mounting.

\section{The results of the measurements}

Analysis of the laser beam using the CARTO software allowed to determine the following types of displacements of the tested axis: positioning accuracy of the $\mathrm{Y}$ axis, twisting the $\mathrm{Y}$ axis in relation to the $\mathrm{Y}$ axis, twisting the $\mathrm{Y}$ axis in relation to the $\mathrm{Z}$ axis, twisting the $\mathrm{Y}$ axis with respect to the $\mathrm{X}$ axis, $\mathrm{Y}$ axis deviation in relation to the $\mathrm{X}$ axis and the $\mathrm{Y}$ axis deviation in relation to the $\mathrm{Z}$ axis.

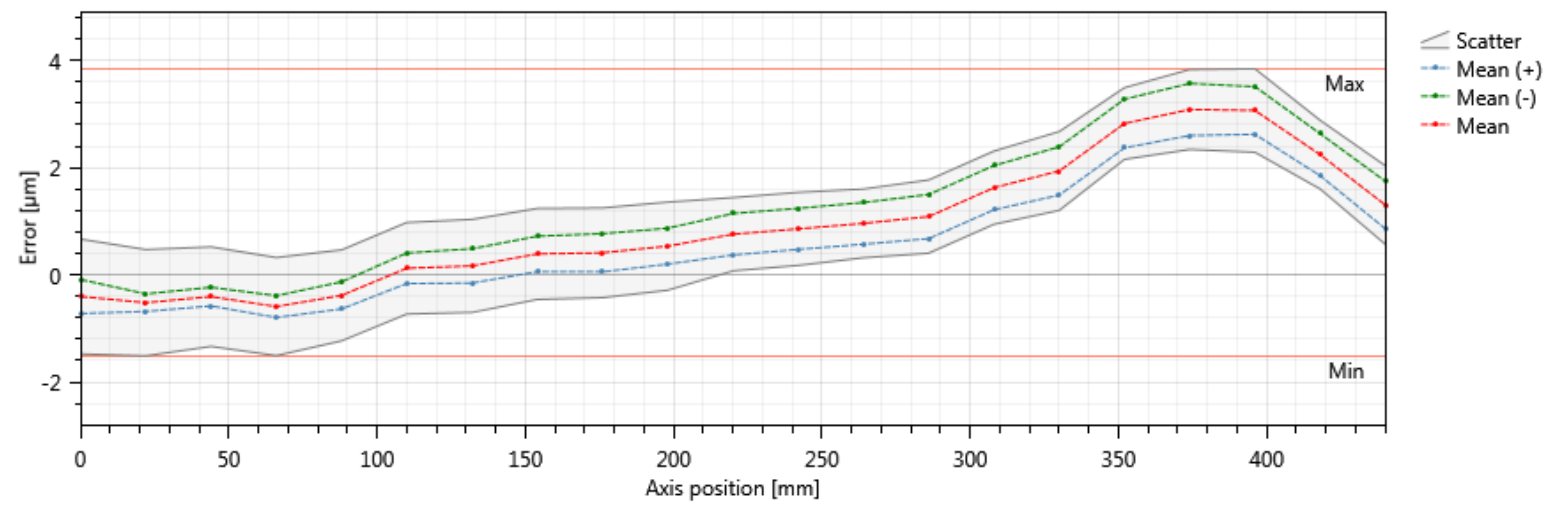

Fig. 2: Measuring the accuracy of $Y$ axis positioning.

Analysis of the $\mathrm{Y}$ axis positioning accuracy (Figure 2) showed that it remains at a low level. In the positive direction, the accuracy was $4.3 \mu \mathrm{m}$, and in the negative direction $4.5 \mu \mathrm{m}$. Bi-directional positioning accuracy was $5.3 \mu \mathrm{m}$. The repeatability of the movements in the positive / negative direction was $1.5 / 0.7 \mu \mathrm{m}$, and the bi-directional was $1.6 \mu \mathrm{m}$. Bi-directional Sys Dev error was equal to $4.4 \mu \mathrm{m}$ (ISO 230-2, 2014). The graph shows a slight deviation in the final spindle travel path. In accordance with the manufacturer's guidelines, the positioning accuracy did not exceed the standard (VDI / DGQ 3441, 1977). The accuracy of the bidirectional angular deflection of the $Y$ axis with respect to the $Y$ axis (Figure 3) was $0.0284 \mu \mathrm{m}$. The average accuracy of repeatability of movements was $0.0231 \mu \mathrm{m}$. The bidirectional error of Sys Dev was $0.0095 \mu \mathrm{m}$ (ISO 230-2, 2014). The analysis of the graph shows that the level of angular deviation remained at a constant low level 


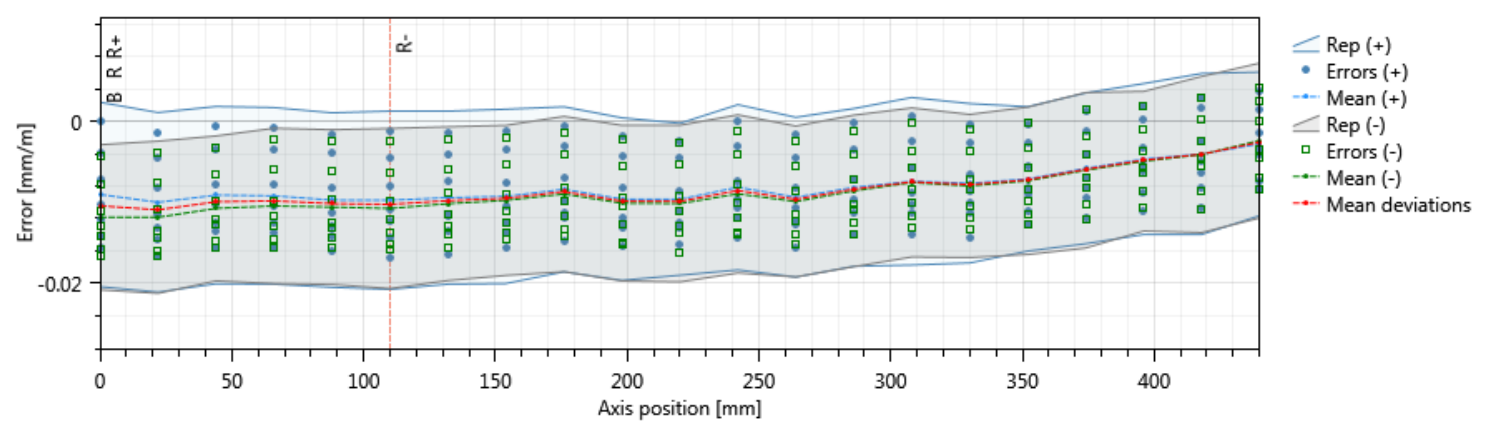

Fig. 3: Measurement of twisting the $Y$ axis in relation to the $Y$ axis.

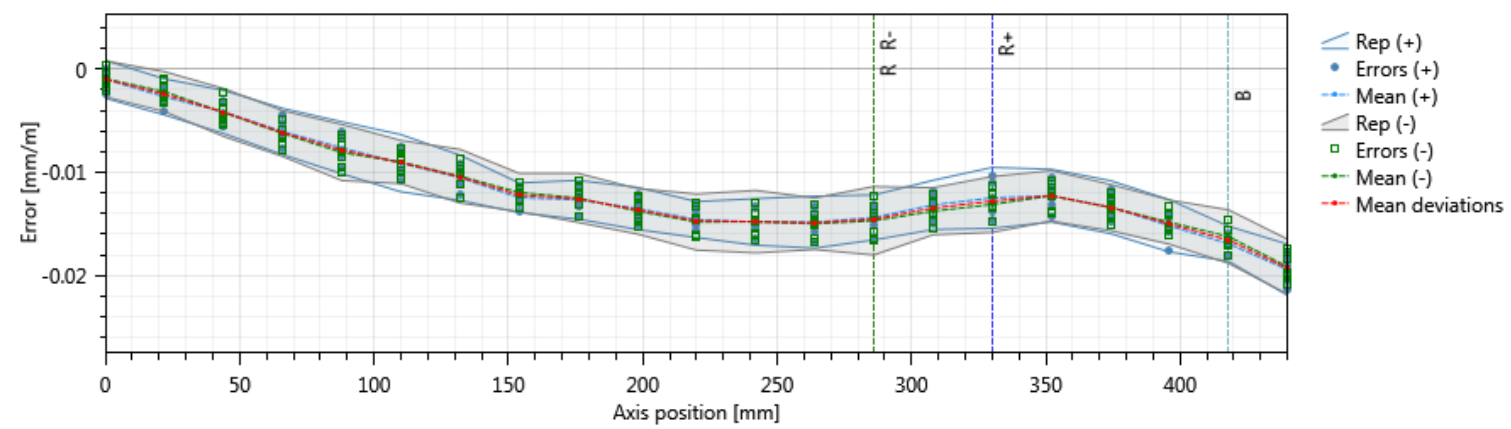

Fig. 4: Measurement of twisting the $Y$ axis in relation to the $Z$ axis.

Analyzing angular deviations (Figure 4), a downward trend can be observed. When performing the displacement, the bi-directional accuracy of the deviation was $0.0228 \mu \mathrm{m}$. The average error of repeatability of movements of the tested axis was $0.0066 \mu \mathrm{m}$. However, the error Sys dev was $0.0185 \mu \mathrm{m}$ (ISO 230-2, 2014).

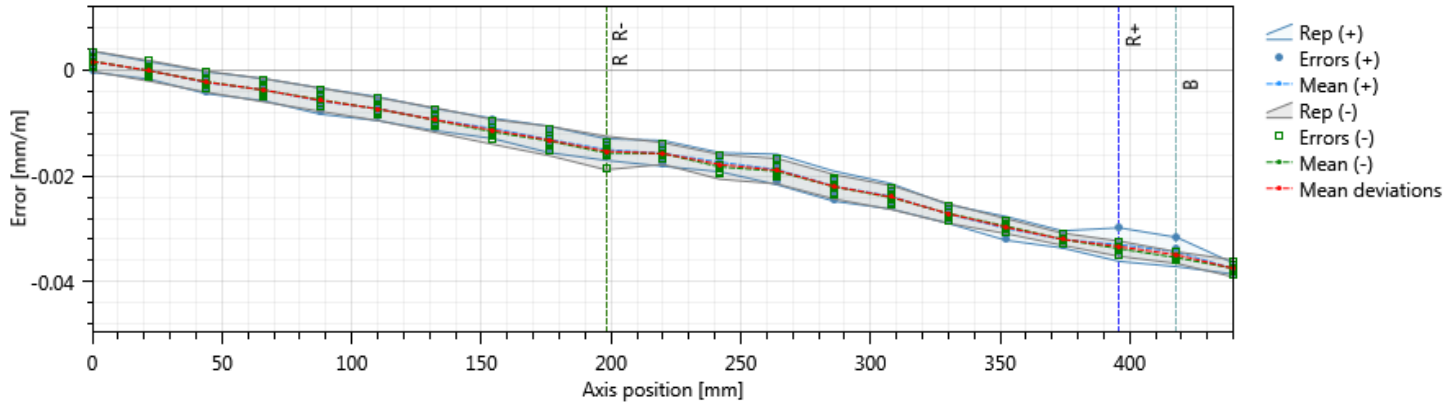

Fig. 5: Measurement of twisting the $Y$ axis in relation to the $X$ axis.

The examined angular deviation (Figure 5) showed that the average accuracy of the deviation was 0.0427 $\mu \mathrm{m}$. Bi-directional repeatability was $0.0064 \mu \mathrm{m}$, while the Sys dev error was $0.0392 \mu \mathrm{m}$ (ISO 230-2, 2014). The tests showed that the maximum deviation for the $\mathrm{Y}$ axis Umax was $7 \mu \mathrm{m}$. (Figure 6) (VDI / VDE 2617, 1987). Based on the data obtained from the axis measurement, it can be read that the maximum deviation for the $\mathrm{Y}$ axis with respect to the $\mathrm{Z}$ axis was Umax $6.7 \mu \mathrm{m}$ (Figure 7) (VDI / VDE $2617,1987)$. Obtained measuring points in various displacement studies coincide with each other, which gives the opportunity to analyze their interaction with each other during the operation of the machine tool. Data obtained during the measurements were referred to the currently valid standards describing the guidelines for diagnostic measurements of $\mathrm{CNC}$ machine. This made it possible to state that the tested machine axis meets the work criteria declared by the machine manufacturer. 


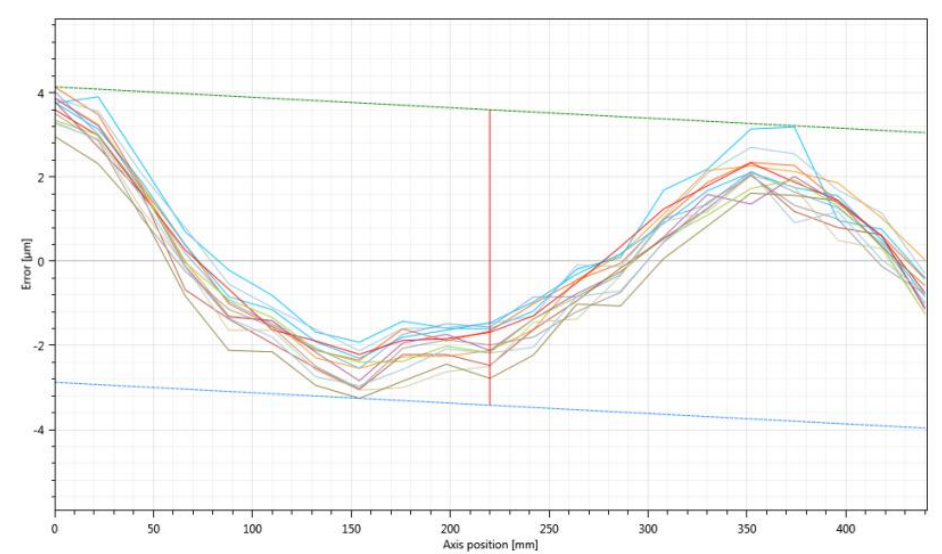

Fig. 6: Measurement of $Y$ axis deviation in relation to the $X$ axis.

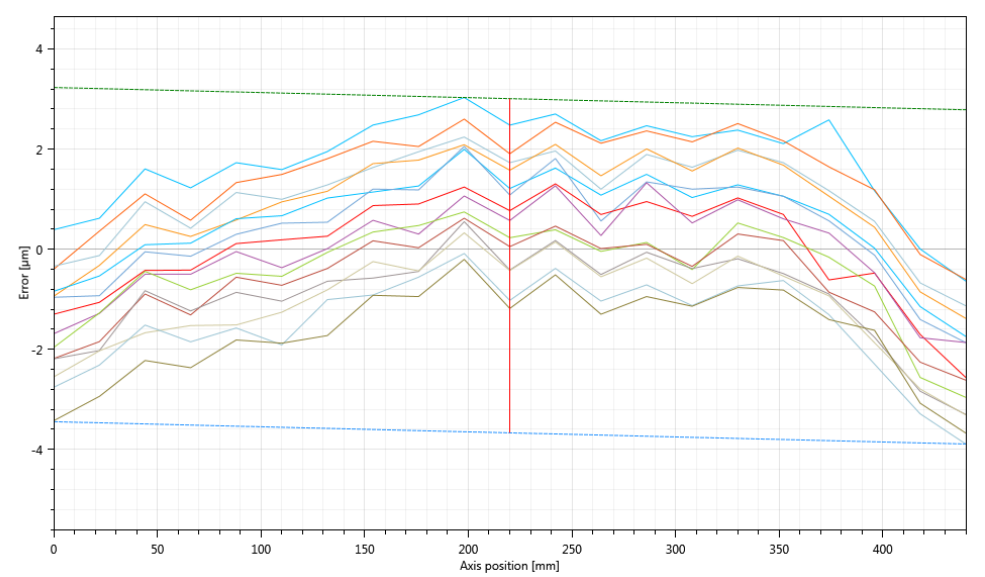

Fig. 7: Measurement of $Y$ axis deviation in relation to the $Z$ axis

\section{Conclusions}

Using of machine condition diagnostic systems has a significant impact on increasing the accuracy of their work. With the development of technology, research apparatus is simplified. This translates into increasing the research capabilities of a given measurement system. This allows to diagnose whether the machine performs its tasks correctly. This allows to determine the impact of individual machine elements on the machining process. Modern research equipment has the ability to perform different types of measurement in one mounting. This shortens the machine downtime and increases the accuracy of the measured data. Using of the XM-60 in the diagnostic process confirmed these arguments. Obtained results were referred to the diagnostic standards of $\mathrm{CNC}$ machines. This allowed to state that the work of the linear axis of a CNC machine refers to the criteria of work accuracy declared by the machine manufacturer.

\section{References}

Honczerenko J. (2009) Obrabiarki sterowane numerycznie, Warszawa.

ISO 230-2:2014(en) (2014) Test code for machine tools — Part 2: Determination of accuracy and repeatability of positioning of numerically controlled axes.

Maj, P. and Miko E. (2014) Pomiary diagnostyczne pionowego centrum frezarskiego. Mechanik, 87, pp. 223-230.

Miko E.and Jarema M. (2012) Badania dokładności pozycjonowania pionowego centrum obróbkowego. Pomiary Automatyka Kontrola, 56, 1, pp. 63-65.

Szafarczyk, M. and ChrzanowskiI J. (2005) Nowa koncepcja sprawdzania dokładności maszyn NC materiały konferencyjne, AUTOMATION, Automatyzacja-Nowości i Perspektywy, Warszawa, pp. 405-413.

VDI/DGQ 3441 (1977) Statistical Testing of the Operational and Positional Accuracy of Machine Tools.

VDI/VDE 2617 (1987) Accuracy of coordinate measuring machines. 